\title{
SUBJETIVIDAD EN AGRUPACIONES DE PERSONAS EN SITUACIÓN DE DISCAPACIDAD: EXPLORANDO LA DUALIDAD SUJECIÓN-AGENCIA Y LA VISIÓN DE DISCAPACIDAD DESDE LA PROPIA VIVENCIA ${ }^{1}$
}

\author{
SUBJECTIVITY IN GROUPS OF PEOPLE WITH DISABILITIES: EXPLORING THE \\ SUBJECTION-AGENCY DUALITY AND THE VISION OF THE DISABILITIES FROM THE \\ OWN LIVING EXPERIENCE
}

\section{Pamela Gutiérrez M. ${ }^{2}$, Raúl Moya V. ${ }^{3}$, Juan Pablo Saa A. ${ }^{4}$, Nicole Yañez H. ${ }^{5}$, Javier Campos M. ${ }^{6}$.}

\begin{abstract}
Resumen:
La discapacidad como constructo social está compuesta por corporalidad, estereotipos y conductas de auto aceptación o negación. La discapacidad tiene implicancias a nivel personal y colectivo, demandando un perfeccionamiento en las perspectivas actuales de acción y comprensión por parte de los profesionales vinculados con esta realidad. Esta investigación se realizó con dos propósitos: explorar las construcciones subjetivas de personas en situación de discapacidad que forman parte de agrupaciones de personas con discapacidad; y describir cómo éstas influyen en su forma de organizarse y en sus ocupaciones. El contacto con los y las participantes se realizó mediante la estrategia de informantes clave, la recolección de datos a través de una entrevista semiestructurada y el método de análisis mediante la técnica de análisis de contenido (categorial). Los resultados muestran dos tendencias de funcionamiento en las agrupaciones que pueden llegar a coexistir en un mismo período. La primera de corte reivindicativo (demandar lo que se considera derecho propio) y la segunda tendencia problematizadora (poner en discusión lo que parece una idea irrefutable). Finalmente, la construcción de las personas se comprende desde la tensión existente entre las prácticas de sujeción y agencia relacionadas a la discapacidad, como la sumisión frente a modelos normativos y/o la crítica a la infantilización y asistencialismo.
\end{abstract}

\section{Palabras Clave:}

Subjetividad, discapacidad, ocupación, agrupación, sujeción, agencia.

1 La presente investigación fue presentada en el 16th International Congress of the World Federation of Occupational Therapists. Yokohama, Japón. Bajo el nombre: "Subjectivity in Groups of People With Disabilities". Saa, Juan Pablo, Gutiérrez, Pamela; Moya, Raúl; Campos, Javier, Yañez, Nicole. El 18 de Junio 2014.

2 Terapeuta Ocupacional, Licenciada en Ciencias de la Ocupación Humana, Doctora en Psicología Social .Profesora Asistente, Universidad de Chile. Avda. Independencia 1027, Independencia, Santiago Chile. 29786545 e -mail de contacto: pamelagutierrez@med.uchile.cl

3 Terapeuta Ocupacional. Licenciado en Ciencia de la Ocupación Humana, Universidad de Chile. Terapeuta Ocupacional, Clínica Los Coihues, Laguna Sur 6561, Estación Central, Santiago Chile. +56954169322 e-mail de contacto: raulmoya.v@gmail.com

4 Licenciado en Ciencia de la Ocupación Humana, Universidad de Chile. Post-professional Doctoral student in Occupational Therapy, Masters in Public Health student, Washington University in St. Louis. +1 314629 0316. saajp@outlook.com

5 Terapeuta Ocupacional. Licenciada en Ciencia de la Ocupación Humana, Universidad de Chile. Terapeuta Ocupacional, Centro de Salud Familiar Dra. Ana María Juricic, Av. El Conquistador 1841, Maipú, Santiago Chile +56978558811 e-mail de contacto: ale.herrera.182@gmail.com

6 Terapeuta Ocupacional. Licenciado en Ciencia de la Ocupación Humana, Universidad de Chile. Subcomisario Policía de Investigaciones de Chile, Brigada de homicidios Metropolitana, Williams Rebolledo 1717, Ñuñoa, Santiago Chile+56962521726 e-mail de contacto: javier. campos.morales@gmail.com 


\begin{abstract}
The concept of disability, defined as a social construct, comprises corporality, stereotypes, and behaviors of self-acceptance or rejection. Subsequent implications of disability at the personal and collective level demand an improvement in its professional comprehension and action. This study's purposes are to explore the subjective constructions of people with disabilities who are members of groups of people with disabilities; and to describe how these constructions influence both occupations and the way people organize as members of groups of people with disabilities. Contact with participants, data collection, and data analysis were completed through key informants, semi-structured interviews, and the Categorical Content Analysis method, respectively. Results revealed two tendencies of group function that may coexist; the first relates to a demanding standpoint - that is, claiming what is believed to be a right; and the second to a problem-causing standpoint - or arguing what seems to be irrefutable -. Finally, subjective construction of individuals was understood as the fine line existing between the subjection-agency practices related to their disability, as well as the submission to normative models and/or the criticism towards infantilization and assistencialism.
\end{abstract}

\title{
Keywords:
}

Subjectivity, disability, group, subjection, agency.

\section{INTRODUCCIÓN}

La discapacidad como concepto y temática de relevancia pública, ha sido tratada desde diversos enfoques (sociales, políticos y sanitarios), que la describen como un término dinámico y complejo. Este constructo conlleva, hasta nuestros días, elementos que suscitan permanente controversia; su evolución, a partir de las transformaciones históricas y paradigmáticas de las sociedades en general, da lugar a un constante debate político-público, que hoy se sitúa desde la perspectiva de derechos (ONU. Organización Naciones Unidas, 2006). Cabe destacar, que éste último enfoque ha sido impulsado por las propias personas en situación de discapacidad, que agrupadas entre sí, han logrado alzar un discurso problematizador de esta realidad.

Con el fin de indagar aspectos relacionados a esta temática, la presente investigación establecerá una vinculación entre los conceptos de discapacidad, agrupación y subjetividad, con el objetivo de profundizar acerca de las interpretaciones, saberes, aspiraciones, características y prácticas sociales que constituyen a un número definido de personas en situación de discapacidad que participan en agrupaciones. Éste último ámbito se explora en el contexto de dos agrupaciones denominadas "de personas con discapacidad", que mantienen una participación social y política activa frente a dicha temática (Montero, 2004).

Como guía de la investigación nos preguntamos: ¿cuál es la subjetividad expresada por sujetos/as que se reconocen como integrantes de agrupaciones de personas en situación de discapacidad?. Con respecto a la interrogante, nuestro objetivo general es:
- Comprender las construcciones subjetivas expresadas por sujetos en situación de discapacidad, que se reconozcan integrantes de agrupaciones de personas con discapacidad.

Para dar respuesta a lo anterior, se plantean como objetivos específicos:

- Indagar en las concepciones personales de discapacidad presentes en el grupo.

- Indagar expresiones de resistencia-agencia en las narrativas de las personas integrantes de las agrupaciones.

- Indagar expresiones de grupo en las narrativas de la población en estudio.

- Explorar aportes para la intervención psicosocial, en particular para la terapia ocupacional.

A continuación se presenta el marco conceptual del trabajo de investigación en torno a las temáticas de subjetividad, discapacidad y formas de agrupación.

\section{Marco CONCEPTUAL}

Aproximación a la subjetividad, discapacidad y formas de agrupación. 
El interés de esta investigación enmarca tres conceptos fundamentales: subjetividad, discapacidad y agrupación. Mientras el primero y el tercero se plantean en base a diversas propuestas teóricas, el segundo se analiza brevemente de forma histórica, abarcando modelos y paradigmas. Estos elementos se vinculan delimitando y clarificando el campo de estudio, en donde se explora el concepto de subjetividad en personas en situación de discapacidad que toman parte activa en agrupaciones sociopolíticas.

Comprendida como la "manera en que nos pensamos y sentimos a nosotros mismos" (Gil, 2004, p. 17), la subjetividad se entiende como un constructo sociohistórico que se origina a partir de discursos, relaciones de poder y saber, cultura, época y construcciones simbólicas. De acuerdo a lo anterior, cada época histórica forja un tipo de sujeto conveniente para el funcionamiento de las ideologías imperantes, el cual aporta a la reproducción y mantención del propio sistema social (Gil, 2004).

Los mecanismos a través de los cuales se construye la subjetividad están relacionadas con las condiciones sociales que nos configuran como sujetos. Éstos elementos son "el conjunto de prácticas que hacen posible al ser humano en tanto sujeto reflexivo, es decir, sujeto de conocimiento de sí mismo, y sujeto que se gobierna a sí mismo" (Gil, 2004, p. 17) prácticas que se expresan en la cotidianeidad de las ocupaciones. En este ámbito, el lenguaje se instaura como un espacio de significantes y significados que constituye y atraviesa al sujeto, permitiéndole mantener una trayectoria estable, expresando y constituyendo su propia subjetividad.

Desde esta perspectiva, un individuo que permanece inmerso en un sistema determinado tendrá una tendencia a repetir comportamientos acordes a la experiencia que éste le entrega. Esta red de prácticas lo definen y caracterizan como un sujeto del sistema, parte de "una red más o menos organizada, jerarquizada, coordinada [del entramado social]" (Foucault, 1978, p. 93). La adherencia o sometimiento a la continuidad del sistema y sus características se denomina sujeción. Así, un individuo en esta condición denota un "comportamiento tal y como puede y debe ser con arreglo al momento histórico y las configuraciones de podersaber"(Amigot, 2005, p. 137).
Sin embargo, toda relación de poder ofrece posibilidades de reacción o actos de resistencia que no se confrontan precisamente con el poder, pero que permiten generar una variación y/o cuestionamiento a aquellas situaciones de sometimiento o sujeción (Amigot, 2005). De tal cuestionamiento emerge la agencia, proceso en el que se problematiza "no solamente al sujeto, sino a la propia acción y a la propia capacidad de actuar" (Ema, 2004 , p. 13). Los sujetos agentes se reconocerán por las "constantes rupturas de códigos, por su alejamiento respecto a los diagramas según los cuales todo ser se estructura, por su permanente tendencia a destituir cualquier forma de totalidad social" (Hurtado Valero en (Amigot, 2005)), de este modo, la sujeción y agencia, se convierten en una continua tensión constitutiva de las sujetividades de las personas.

Desde este enfoque, la noción de discapacidad ha generado sujetos acordes a los contextos sociohistóricos sucedidos en épocas específicas. Históricamente, este concepto ha hecho referencia a sujetos denominados como: "no capaz", "no hábil", "no digno", "no apto" o que "no tiene cabida", "un uso del lenguaje que porta connotaciones expresamente negativas" (Droguett, 2008, p. 39) como "yo roto, imperfecto o incompleto" (Egea \& Sarabia, 2001, p. 15).

Actualmente, la Clasificación Internacional del Funcionamiento, de la Discapacidad y la Salud (CIF), define discapacidad como un término genérico que incluye deficiencias, limitaciones en la actividad y restricciones en la participación; enfatizando, entre otros, los aspectos negativos existentes en la interacción entre el individuo y su contexto (Querejeta, 2004).

Considerando que la subjetividad de los individuos es un constructo variable, cuyas modificaciones se generan en función de los sistemas de reproducción y los paradigmas imperantes en una época histórica, el concepto de discapacidad - y los propios sujetos - tienen un potencial de cambio en cada una de éstas. En la actualidad, se aprecia un desarrollo conceptual cuyo origen progresa desde la visión estigmatizadora de la discapacidad hacia una perspectiva social inclusiva e integradora de la misma, como se señala en la figura 1. 
Fig. 1

Modelos de la Discapacidad dominantes según periodo histórico

\begin{tabular}{|c|c|}
\hline $\begin{array}{c}\text { Modelo Preformista o Negativista (Hasta s. } \\
\text { XVII) }\end{array}$ & $\begin{array}{c}\text { Las deficiencias se preforman en el momento o son el resultado de designios } \\
\text { de fuerzas divinas. }\end{array}$ \\
\hline $\begin{array}{c}\text { Modelo Predeterminado Médico (s. XVII - } \\
\text { s. XIX) }\end{array}$ & $\begin{array}{r}\text { Las discapacidades tienen origen biomédico. Las órdenes religiosas son funda- } \\
\text { mentales en este ámbito. }\end{array}$ \\
\hline $\begin{array}{c}\text { Modelo Determinista Funcional (s. XIX - } \\
\text { 1980) }\end{array}$ & Se desarrolla el concepto de rehabilitación y de educación especial. \\
\hline $\begin{array}{c}\text { Modelo Interaccionista o Estructuralista } \\
\text { Modelo Inclusivo de los Derechos Huma- } \\
\text { nos (DD.HH.) }\end{array}$ & $\begin{array}{r}\text { Se da énfasis al concepto de desventaja y a considerar los factores ambienta- } \\
\text { les. Importancia de eliminar las barreras físicas y estructurales. }\end{array}$ \\
ción igualitaria de las Personas en Situación de Discapacidad.
\end{tabular}

Fig.1 Adaptación propia del contenido "La evolución de la Discapacidad" en "Inclusión de la Niñez con Discapacidad" Instituto Interamericano del Niño - Organismo especializado de la OEA. (Intituto Interamericano del niño, 2001).

Los orígenes de los cambios en relación a la discapacidad $^{7}$ se han producido, en gran parte, por la aparición y consecuente influencia de movimientos y agrupaciones de personas con discapacidad, como es el caso del movimiento estadounidense de Vida Independiente (Dejong, 1978), cuyo objetivo fue conceptualizar el fenómeno de la discapacidad, dando una respuesta al reto de definir y localizar éste concepto, proponiendo al mismo tiempo cuáles son sus principales actores y soluciones (García-Alonso, 2003).

En la actualidad, la existencia de variadas agrupaciones refleja una tendencia a poner en tensión las estructuras y conceptualizaciones generadas en torno a la discapacidad. Las tendencias de cada agrupación se generan en base a los intereses, percepciones, aspiraciones y saberes de cada uno de sus miembros. Así, cada agrupación puede establecer prácticas de reproducción o agencia de acuerdo a los objetivos perseguidos y la postura que se proyecten respecto al tema.

Para comprender una agrupación es importante visitar el concepto de grupo, el cual se entiende como la unidad de una pluralidad constituida por personas que comparten valores, actúan de acuerdo a normas establecidas, e interactúan entre ellas (Martín-Baro, 1989). A su vez, y complementando con la perspectiva de los

\footnotetext{
Al respecto, en esta investigación se considera la coexistencia de diversos paradigmas en la intervención psicosocial (Gutiérrez, 2014, p. 116) .
}

movimientos sociales, las agrupaciones se vuelven organizaciones cuando existe una coordinación formal de sus miembros en torno a una problemática o contexto de crisis (Valenzuela, 2007). Por su parte, los colectivos, actúan bajo un consenso sin formalidades. De acuerdo a Salazar y Pinto (2002), en un colectivo todos los miembros piensan, deciden y actúan; no hay censura, no hay jefes; la representatividad se limita a los que quieren participar, es decir, la participación subordina la representatividad (Salazar \& Pinto, 2002).

Tanto colectivos como organizaciones son parte importante de los movimientos sociales, cumpliendo con cinco características comunes: tener un desafío colectivo, una meta común, un sentido de solidaridad y una identidad, siendo quizás lo más característico e importante el mantener una acción colectiva (Garcés Montoya, 2010).

Es de valor señalar algunas de las características de las agrupaciones que pueden verse reflejadas en los tipos de agrupaciones de personas en situación de discapacidad del presente estudio. En términos generales, ambas formas de agruparse pueden ser diferenciadas al explorar las dinámicas de participación que muestran sus integrantes, así como sus prácticas y/o tendencias a la sujeción o la agencia.

Cabe destacar que la participación en agrupaciones de las mujeres con discapacidad, se da como parte de sus ocupaciones cotidianas, por lo que en ésta investigación se entenderá por ocupación, los desarrollo elaborados en el ámbito disciplinar de la terapia ocu- 
pacional ${ }^{8}$, entendiendo por ésta "aquella actividad con sentido en que la persona participa cotidianamente y puede ser nombrada por la cultura" (Álvarez, E, et al, 2007). Y en una comprensión, que las ocupaciones tienen una dimensión performativa, y al estar íntimamente vinculada a los procesos del "hacerse" (Gutiérrez, P. y Pujol, J., 2016), esta participación en ocupaciones, tiene implicancias en la construcción subjetiva de los y las sujetos integrantes de agrupaciones.

\section{Metodo}

El presente estudio cualitativo, aborda la problemática de investigación desde un enfoque construccionista, desde el cual busca comprender y generar conocimiento (Berger \& Luckmann, 1966; Berger, Luckmann, \& Zifonun, 2007), desde esta perspectiva, el relato de los y las participantes permitirá construir un entendimiento de las problemáticas desde las mismas bases de su vivencia, ya que "es a través de una apreciación crítica del lenguaje como podemos alcanzar la comprensión de nuestras formas de relación con la cultura y, a través de él, abrir un espacio a la consideración de las alternativas futuras" (Gergen, 1996, p. 71). Desde esta perspectiva, las narraciones de los y las sujetos serán la principal fuente de información, así, la entrevista semiestructurada es utilizada como fuente de recolección de datos. Ésta permitirá aproximarse a una determinada realidad, atendiendo, esencialmente, a nuestro objetivo de estudio. El carácter de las entrevistas favorecerá la flexibilidad, el dinamismo y apertura, en base a lineamientos establecidos en formato de pregunta, que guiarán las narraciones de acuerdo a los objetivos del estudio. La información es registrada a través de grabaciones y/o notas, de acuerdo a lo planteado en el consentimiento informado firmado por cada entrevista

La estrategia para sistematizar la información recopilada corresponde al análisis de contenido, la cual permitirá "formular, a partir de ciertos datos, inferencias reproducibles y válidas que puedan aplicarse a su contexto" (Krippendorff \& Wolfson, 1990, p. 28), gene-

8 "La Terapia ocupacional es una profesión de la salud centrada en el usuario, a la cual le concierne la promoción de la salud y el bienestar a través de la ocupación. La finalidad primordial de la Terapia ocupacional es posibilitar la participación de las personas en las actividades de la vida cotidiana" (WFOT, 2010) rando reflexiones y aportes conceptuales de relevancia para la terapia ocupacional en su vinculación con en este grupo de personas. Por medio del análisis de contenido, la información se sintetiza en categorías investigativas, lo que hace posible categorizar temáticamente y este punto, generar las conclusiones del estudio.

Durante el proceso de recolección de la información, se realizó una aproximación etnográfica (Gutiérrez \& Pujol, 2009) y se realizaron notas de campo, las cuales no fueron incluidas en el análisis posterior, debido a limitaciones de tiempo que influyeron en el desarrollo del estudio, sin embargo, permitieron ampliar y profundizar la comprensión de la presente investigación.

\section{Población de estudio y Criterios de Inclusión}

La muestra de estudio está conformada por 4 personas en situación de discapacidad pertenecientes a 2 agrupaciones (asociación-colectivo) situadas en la Región Metropolitana (ver fig. 2).

La selección de los participantes se define mediante los siguientes criterios de inclusión:

- Persona en situación de discapacidad física o sensorial.

- Mayor de 18 años.

- Participante de una agrupación denominada "de personas con discapacidad".

- Participación regular de encuentros reuniones acordadas por la organización.

En tanto, los criterios de exclusión son:

- Persona con dificultad para expresar verbalmente su experiencia.

La estrategia de obtención de información es realizada mediante el contacto con "informantes clave" y la técnica de "bola de nieve" (Taylor \& Bogdan, 1984). Dado que, por medio de los informantes clave se pretende contacto a otros participantes de las respectivas agrupaciones. Conjuntamente, el muestreo de los participantes es no randomizado, es decir, la selección de un individuo particular se relaciona al beneficio que pueda otorgar a los objetivos de este estudio. 
Fig. 2

Caracterización de los y las entrevistados/as:

\begin{tabular}{|c|c|}
\hline Entrevistado/a & Descripción de la agrupación \\
\hline Luis & Pertenece a una agrupación que reúne a personas con diferentes tipos de discapacidad y también a \\
personas sin discapacidad.
\end{tabular}

\section{Resultados}

De acuerdo al análisis de contenido llevado a cabo en cuatro entrevistas, aplicadas en una única oportunidad, se obtienen grupos de datos organizados en diez categorías (Fig. 2) que guardan relación con los aspectos considerados relevantes para los objetivos de esta investigación y elementos emergentes en los discursos de los y las entrevistado/as.

Fig. 2

Categorías

\begin{tabular}{|c|c|}
\hline Categorías Principales & Categorías Emergentes \\
\hline Concepto de Grupo & Conflicto con la autoridad \\
Concepto de Discapacidad & Cuerpo \\
Sujeción & Sentido de pertenencia \\
Crítica- Problematización & Experiencia de discriminación \\
& Áreas problemáticas de la ocupación \\
& Propuestas \\
\hline
\end{tabular}

\section{A) Concepto de Grupo}

Las entrevistas dan cuenta de dos visiones personales respecto al concepto de grupo: una mirada asociada a la propia agrupación y otra relacionada con similares externos; ambas en relación a la composición, dinámicas y propósito del grupo.

Con respecto a la mirada desde la propia agrupación, Victoria señala que existen "instituciones de ciegos e instituciones para ciegos" (Extracto entrevista Victoria, pp. 44), estructura que se reproduce a nivel general entre las agrupaciones. Mientras en las primeras, la organización y dirección recae en las propias personas ciegas; en las segundas estas funciones son ejercidas por personas no ciegas, siendo sus acciones dirigidas hacia éstas.
Los y las entrevistado/as forman parte de aquellas agrupaciones denominadas "de" personas con discapacidad, reuniendo a integrantes con el mismo o con diversos tipos de discapacidad. En este perfil de agrupaciones, la participación de personas sin discapacidad se ve delimitada por las necesidades, el funcionamiento y los intereses de la agrupación y sus participantes. Es decir, se acepta el ingreso y participación de personas sin discapacidad en la medida que cumplan un rol que les sirva dentro de la agrupación. Por ejemplo, en la agrupación $X$, se contrato a una secretaría que no tenía discapacidad ya que les ayudaba a organizarse en las reuniones a través de las actas y otras cosas.

Respecto de los propósitos y dinámicas grupales descritas por los y las entrevistado/as, éstas se aproxi- 
man a la perspectiva reivindicativa y problematizadora. En la perspectiva reivindicativa, el grupo y sus integrantes buscan representación de todo tipo, generando demandas en relación a bienes y/o servicios que se consideran un derecho. De esta manera, la administración de este tipo de agrupación intenta cubrir las necesidades imperantes de sus afiliados, fomentando sus lazos y sentido de pertenencia.

Desde la perspectiva problematizadora se ponen en tensión aspectos de la realidad que parecen irrefutables; los integrantes se identifican con una mirada crítica que promueve un cambio ideológico respecto a la discapacidad, luchando por el respeto y cumplimiento de sus derechos, más que por una ganancia material y tangible.

Ambas perspectivas pueden llegar a coexistir en una misma agrupación, dependiendo de los intereses y necesidades de sus integrantes, y las características distintivas que marcan la autenticidad de cada agrupación. En relación a estas tendencias, Lucas declara "(...) nos interesa ir a los temas de fondo (...) trascender al egoísmo, trascender la onda politiquera barata. El discurso vacío e ir a una cosa más profunda (...) para el conjunto de las personas con discapacidad" (Extracto entrevista Lucas, pp. 63). De la misma manera, María explica: "(...) entre los objetivos está velar por los derechos del ciudadano, obtener ciertos beneficios como el derecho a voto, a la escolaridad. Ser considerado, en el fondo, persona dentro de la sociedad" (Extracto entrevista María, pp. 1).

Respecto a la visión de las otras agrupaciones existentes, los relatos de los y las entrevistado/as denotan una tensión en relación al propósito, los lineamientos, $y / o$ funcionamiento de las otras agrupaciones. Al respecto, Lucas menciona: "“ $\mathrm{X}$ ", "Y", " $\mathrm{Z}$ " y otras organizaciones, son organizaciones que en general reivindican cosas (...) éstos serían los que pelean por los votos del paquete de rinso ${ }^{9}$..." (Extracto entrevista Lucas, pp. 63); mientras María describe que persiste en ellas una visión asistencialista frente a la discapacidad, al señalar que "más que todo beneficios sociales y de rehabilitación (...) hasta cuando cambie el enfoque asistencialista que tienen la mayoría de las instituciones. De hecho esta institución nació bajo el alero de la Mutualidad en donde todo era asistencialista... hoy día hay un cambio en el que las instituciones se están profesionalizando... o intentando por lo menos, y que sea otro el enfoque "(Extracto entrevista María, pp. 3).

\footnotetext{
9 Marca de un detergente.
}

\section{B) Concepto de Discapacidad}

Los y las entrevistado/as destacan el cambio de enfoque en el concepto de discapacidad, el cual se aleja de la perspectiva de las falencias y se centra en la diversidad.

En sus inicios, la discapacidad fue comprendida como una condición "anormal", es decir, situada fuera de los parámetros inculcados como "esperables" por la sociedad (IIN,2001). En base a esta perspectiva, Lucas nos señala: "eso que pudiera parecer trivial, pedestre (...) no lo es en lo absoluto. Eso es la expresión de que para la mayor parte de las personas, las personas con discapacidad están en una situación distinta, en una situación de inferioridad respecto al resto, no es asumido como algo normal y eso es parte de la ignorancia" (Extracto entrevista Lucas, pp. 69). Así, no sólo se entiende que la discapacidad era comprendida como una condición distinta a la norma, sino que también se encontraba en un nivel social inferior, en comparación con las demás personas.

A su vez, las relaciones de poder en una sociedad también explican la discapacidad en función de los valores y prejuicios. Así, el sujeto se identifica con aquellas "ideas preconcebidas", la cuales son impuestas, arraigadas y compartidas. Con respecto a este proceso, Lucas señala que "(...) siendo la discapacidad una construcción social (...) que se hace desde la sociedad hacia el individuo, me parece que eso impacta en el individuo mucho más en la medida en que el individuo internaliza eso y lo asume como parte de su propia limitación" (Extracto entrevista Lucas, pp. 66). Desde esta aseveración, se distingue la "construcción subjetiva" de la discapacidad en función del entramado social y la identificación con conceptos que prevalecen en el contexto social.

Respecto a las formas de resistir dichas concepciones, Carlos declara que "en la medida que aceptes la discapacidad puedes después integrarte al resto del mundo. Parte entonces por aceptarte y quererte tal como eres. Es un proceso largo y no un proceso que va de un día para otro" (Extracto entrevista Carlos, pp. 27).

En la actualidad, si bien la discapacidad aún mantiene una valoración negativa o concepciones relativas a la "anormalidad o variación de la norma", se puede apreciar una integración y/o adopción significativa con el enfoque de "diversidad". Desde esta mirada María refiere: "discapacidad es tener capacidades diferentes no es como algo invalidante, (...) es tener distintas características o capacidades que, en el caso de la visual, 
te limitan a algunas cosas (...) en general es tener capacidades diferentes" (Extracto entrevista María, pp. 6).

\section{C) Sujeción}

Las prácticas de sujeción referidas por los y las entrevistado/as se pueden clasificar en: negación de la discapacidad (normalización), reproducción de modelos tradicionales (asistencialista/ funcional/ biomédico) y prácticas de segregación.

1. Negación de la discapacidad (normalización): de acuerdo al relato de Lucas, el encubrimiento o evasión de las diferencias existentes respecto del "modelo normativo" hacen referencia a una falta de aceptación personal. Al respecto, Lucas comenta: "Durante mucho tiempo arriesgué mi vida de una manera muy estúpida al no asumir la limitación objetiva (...) eso hace que esa limitación se agrande y se transforme en otras limitaciones que son limitaciones que están en la cabeza, que no están en los ojos en mi caso" (Extracto entrevista Lucas, pp. 64-65), "(...) tení que usar el bastón pero no lo hací (haces) porque te da vergüenza" (Extracto entrevista Lucas, pp. 68).

Otra práctica recurrente de sujeción dentro de este contexto es asumir que la discapacidad es una desventaja respecto a otros. Tal como se señala en la cita anterior, en la que se observa la sumisión frente a prejuicios construidos socialmente, que limitan el propio actuar a las disposiciones sociales existentes frente a la discapacidad. En referencia esto Lucas y Victoria mencionan, respectivamente: "(...) era lo que me hacia autolimitarme: que yo asumí todos los prejuicios. Que yo no puedo, que yo no sé que, que no me van a pescar, que no me van a querer, que no voy a tener amigos, que no voy a tener polola, que no voy a tener pega, etc." (Extracto entrevista Lucas, pp. 66). "La discapacidad es obviamente que la disminución o la desventaja que uno tiene contra las personas sin discapacidad, que son una... es una desventaja." (Extracto entrevista María, pp. 45).

2. Reproducción de los modelos tradicionales (asistencialista-biomédico): Lucas menciona que "(...) Las organizaciones tienden a reproducir el modelo tradicional como te decía, están agrupadas por tipo de discapacidad. Hay mucho clientelismo (...) utilización personal de la organización para fines particulares" (Extracto entrevista Lucas, pp. 74)., mientras María señala "(...) hay instituciones de personas con discapacidad visual que todavía funcionan desde el asistencialismo" (Extracto entrevista María, pp. 5). A través de estos enunciados se puntualiza la existencia de personas que actúan como "receptoras" de beneficios otorgados por organizaciones "benefactoras", que funcionan y se constituyen desde una perspectiva asistencialista, involucrando un actuar pasivo y receptor de ayuda de sus miembros. Y un modelo biomédico que subdivide por tipos de discapacidad.

3. Prácticas de segregación: los relatos de Lucas y Carlos dan cuenta de la presencia de decisiones grupales específicas y consensuadas, que limitan la participación de personas sin discapacidad: el énfasis se da en la diferencia entre discapacidad/no discapacidad, como un proceso de tensión y aprendizaje para establecer un sentido de pertenencia al grupo: "hicimos este llamado amplio y nosotros aceptamos gente sin discapacidad pero tienen que tener claro ... los que la llevamos somos nosotros y pueden venir a escuchar ... así como una cuestión súper fascista digamos ... casi de como, ustedes vienen $\mathrm{pa}^{\prime}$ acá pero se tienen que quedar caIladas, como que habían dos ... militancias de segunda categoría ahí, en ese sentido..., entonces yo te diría que ahora, el requisito actualmente, que eso está en discusión ya, en debate permanente, es...eh ... tener algún tipo de discapacidad" (Extracto entrevista, pp. 59).

\section{D) Crítica-Problematización}

En las formas de resistencia manifestadas por los/ las entrevistado/as, se visualizan cuatro niveles. En primer lugar, se aprecian críticas respecto a las prácticas de normalización y asistencialismo; en segundo lugar, se postula el accionar colectivo como un medio para conseguir objetivos comunes; en tercer lugar, se valora el lenguaje como acción concientizadora; y en cuarto y último lugar, se manifiestan prácticas de resistencia frente a la institucionalidad.

En relación a las críticas frente a la perspectiva normalizadora de la discapacidad: Lucas señala que "(...) es muy potente en Chile la ideología, lo que se llama la ideología normalizadora: (...) hay un parámetro que tú siempre tienes que cumplir y el que está afuera de eso es el raro" (Extracto entrevista Lucas, pp. 73). La cita refleja el profundo asentamiento de criterios que definen que es lo apropiado y que escapa de la normalidad en la sociedad Chilena actual. Esta configuración influye negativamente en los procesos de inclusión social (no sólo de las personas en situación de discapacidad), promoviendo la homogenización y negación de la diversidad, fomentando la discriminación y la desigual- 
dad. De la misma forma, respecto a las consecuencias de esta ideología, Lucas refiere: "(...) las personas que están ahí no les interesa el colectivo, se interesan a sí mismo. Se reproduce esta lógica del egoísmo, del individualismo. Del que yo estoy ahí porque quiero estar ahí,... y utilizo la organización para mis objetivos (...)" (Extracto entrevista Lucas, pp. 63). En donde se instala la lógica de una sociedad individualista, que privilegia los intereses personales frente a las acciones colectivas, resaltando, finalmente, la inconveniencia de la diferencia, el accionar conjunto y la defensa de los intereses comunes.

Asimismo, una propuesta común en los relatos de los y las entrevistado/as es la reprobación - desde diversas perspectivas - de las prácticas asistencialistas. Al respecto, Lucas menciona que "la gente asume que tú, por tener una limitación necesitas necesariamente una ayuda y eso no es así (...) lo correcto es que yo decida cuando necesito ayuda y yo decida que tú me ayudes (...)" (Extracto entrevista Lucas, pp. 70). Lo que pone en evidencia el impacto negativo del asistencialismo en la consecución de derechos y autonomía, al reproducir un estereotipo de la discapacidad vinculado a la ausencia de capacidad y lástima. En el mismo contexto, Lucas expresa un profundo desacuerdo con la metodología de funcionamiento de las instituciones u organizaciones, cuya visión se establece únicamente desde la beneficencia, afianzando su discrepancia frente al desmedro en la representatividad de las personas en situación de discapacidad "(...) nosotros si queremos hacer ponte tú, una manifestación pública, a propósito de la "Institución X" (...) no sé si contra la "Institución X" pero al menos para manifestar algunas de las cosas que a nosotros nos parecen pertinentes, la transparencia, el hecho del enriquecimiento de las empresas y personas gracias a la discapacidad (...)" (Extracto entrevista Lucas, pp. 56).

En segundo lugar, respecto a los beneficios del accionar colectivo, la participación al interior de una agrupación es visualizada por los y las entrevistado/as como una oportunidad para poner en práctica, mediante acciones concretas, el sentido crítico planteado desde la "teoría", el "deseo" o las "aspiraciones". En este punto, Lucas plantea: "(...) ¿usted cree que va a hacer algo solo? si usted tuviera un problema y lo discriminan usted cree que va a ser algo mejor mandando solito una carta al SENADIS ${ }^{10}$ (...) usted cree que va a ser

\footnotetext{
10 Servicio Nacional de Discapacidad.
}

mejor eso o apoyado por otras personas que están en su misma situación/condición (...). En la acción muchas manos hacen mucha más fuerza que una sola mano" (Extracto entrevista Lucas, pp. 64). De modo similar, en ambas agrupaciones se plantea la importancia de la participación colectiva para conseguir un objetivo, que variará de acuerdo al nivel de organización-articulación, intereses, acuerdos comunes y empatía entre sus miembros.

En tercer lugar, el lenguaje es también considerado un sustrato para quebrantar las relaciones de poder establecidas mediante éste (o asimismo, reproducirlas). Frente a esto Carlos expresa: "tenemos que formar líderes, concientizar, al poto hay que decirle poto para remecer las consciencias, no podemos decirle popín, (...), hablar crudo (...), no son vulnerables, son pobres, (...) Lo real" (Extracto entrevista Carlos, pp. 37). En este sentido, el cómo se defina en el lenguaje, influirá en la comprensión-conformación de sí mismo y del colectivo, así como el nivel de reflexión y problematización que pueda alcanzarse frente a los hechos.

Finalmente, se enuncia la acción política como una práctica de resistencia frente a la institucionalidad, que promueve la toma decisiones de manera autónoma, la protección de los derechos personales y el ejercicio de la autodeterminación. Tal como enuncia Carlos, en referencia a su propia agrupación: "(...) si nos invitan a algún seminario en SENADIS vamos como colectivo y nos distribuimos de tal forma en las comisiones cosa de hacerlos mierda, en el sentido de que queremos avanzar. Como te dije antes, basta del diagnóstico, el diagnóstico ya lo conocemos (...)" (Extracto entrevista Carlos, pp. 25).

\section{E) Conflicto con la autoridad}

La presencia de relatos que describen conflictos con la autoridad es recurrente y similar entre los y las entrevistado/as, quienes manifiestan un primer plano de tensión, entre la población en situación de discapacidad y los organismos de gobierno; y un segundo plano, entre las personas en situación de discapacidad y los "expertos" en el tema.

Respecto al primer plano de tensión, Carlos expresa que las políticas establecidas para las personas en situación de discapacidad no contemplan la participación efectiva de esta población en lo que respecta a necesidades y planteamientos internos: "(...) eso no es posible, o sea si van a hablar de ti tienes que estar tú 
presente poh, entonces no es posible que hagan un diagnóstico y después negocien a puertas cerradas" (Extracto entrevista Carlos, pp. 25).

Asimismo, frente al segundo plano de conflicto Carlos revela una tendencia generalizada a tomar las decisiones desde la perspectiva del saber científico, sin que ésta considere aquellos saberes dominados por las propias personas: "(...) todos quieren tomarse la posesión de la discapacidad (...) los expertos y dejar afuera o dejar en menos porcentaje a las personas con discapacidad". (Extracto entrevista Carlos, pp. 22).

En general, se considera que, tanto los organismos estatales como los expertos, presentan un bajo nivel de trabajo cooperativo con la población aludida. En este sentido, existe un cuestionamiento por parte de las agrupaciones participantes respecto al abordaje social y gubernamental de la discapacidad, que denota una escasa representatividad de los intereses, necesidades y aspiraciones reales de esta población frente a temas que les corresponden directamente.

\section{F) Cuerpo}

Los relatos de los y las entrevistado/as denotan una tensión entre los conceptos de discapacidad y cuerpo, percibidos y experimentados de manera profundamente personal. Respecto a este hecho Carlos menciona: "(...) Yo puedo caminar, puedo correr, puedo saltar, lo único que no puedo hacer es salir a robar en las micros" (Extracto entrevista Carlos, pp. 28), "Me acepté desde siempre, incluso te puedo decir que me preocupa que esté más gordo a que me falte una mano (...)" (Extracto entrevista Carlos, pp. 31). Lucas, por otro lado, expresa (en referencia a su pasado) "Para mí la discapacidad siempre fue una limitación. Yo siempre estuve en un entorno familiar muy protegido. En un entorno escolar también muy protegido (...) la primera vez que entré a la universidad yo no hablaba del tema. Me costó mucho. Me eché un ramo (...) porque no veía la pizarra" (Extracto entrevista Lucas, pp. 64).

En las narrativas se observa la influencia que posee la interacción entre "cuerpo y discapacidad" en la constitución de la esfera subjetiva de una persona. Lo anterior puede implicar mirarse a sí mismo desde una perspectiva de limitación o desventaja frente a otros o por el contrario, desde una mirada que valora las habilidades personales, así como la diversidad de cuerpos y funcionalidades existentes.
Retomando la categoría de sujeción previamente expuesta, se distingue que los y las entrevistado/as cursan procesos cíclicos que los sitúan en ambas perspectivas o miradas. Esta dualidad se comprende al tener en cuenta que el modelo normativo de sujeto se encuentra en la sociedad de forma permanente y se muestra naturalizado, siendo reproducido por diversas fuentes sociales (medios de comunicación, publicidad, instituciones, entre otros).

\section{G) Sentido de Pertenencia}

Se visualizan en esta categoría tendencias a la generación de un sentido de pertenencia con la propia agrupación y otra con énfasis al conjunto general de personas en situación de discapacidad.

Respecto a la importancia y sentido de ser parte de una agrupación de personas con discapacidad, Lucas distingue la pertenencia a un grupo como un espacio de participación privilegiado, con aspectos positivos a nivel personal y colectivo: "(...) el hecho de tener un espacio donde hay otros como yo que están dispuestos a dar la pelea por las cosas que a mí me pasan, sin lugar a dudas es fundamental..." (Extracto entrevista Lucas, pp. 74).

A su vez, también se expresa un sentido de pertenencia general respecto a la población de personas en situación de discapacidad. Tal como menciona Lucas, la existencia de características en común emplaza a los sujetos a agruparse para buscar soluciones en conjunto: “(...) cuando tú participas y te organizas y cuando te encuentras con otros y te reúnes y compartes, es cuando realmente tiene sentido, (...) el sentido de nuestra vida estando con personas con deficiencia, en situación de discapacidad, es reivindicar nuestra situación y a partir de ella luchar por mejorar nuestras condiciones de vida (...)" (Extracto entrevista Lucas, pp. 73).

Los y las entrevistado/as destacan la importancia de agruparse con el fin de compartir experiencias, objetivos e ideales, apoyarse y aproximarse a las realidades y necesidades colectivas a partir de las propias. Esto está relacionado con lo señalado anteriormente en el aparado de crítica- problematización, cuando se refiere a los beneficios del accionar colectivo.

\section{H) Experiencia de Discriminación}

De acuerdo a los datos aportados por los y las entrevistado/as, las experiencias de discriminación afec- 
tan de manera general a las personas en situación de discapacidad. Tal como menciona Lucas, éstas se hacen presentes en situaciones cotidianas y se relacionan con estereotipos: "(...) cuando la gente te va a ayudar, ¿Qué es lo que hace la gente? La gente te toma, te agarra, como cuando tú vai a agarrar un gato, un perro, o un papel o un basurero, o la grabadora, el bolso, lo que sea, como que tú fueras un objeto (...) y te dice "venga pa' aca", (...) asumiendo que tú no sabes, de partida dónde vas (...)" (Extracto entrevista Lucas, pp. 70).

Del enunciado anterior se desprende que los eventos de discriminación percibidos por algunas personas en situación de discapacidad, están influenciados por una visión asistencialista e infantilizadora de la persona en situación de discapacidad, que al ser reproducida socialmente establece un estereotipo de "incapacidad" que se arraiga en las prácticas cotidianas. En este sentido, Victoria expresa: "(...) en esa época trabajaba "H. G." quien era un periodista bien conocido (...) Gasté una hora de teléfono convenciéndolo para que nos dijera ciegos, y no nos dijera cieguitos o no videntes, o invidentes." (Extracto entrevistaVictoria, pp. 47). De esta manera, numerosas prácticas sociales referidas a esta población conciben ampliamente a las personas en situación de discapacidad como individuos que requieren apoyo continuo para tomar decisiones y con dificultades para ejercer soberanía sobre sus propias vidas.

\section{I) Áreas problemáticas de la ocupación}

Entre los relatos de los y las entrevistado/as se describe la existencia de dificultades en tres áreas de desempeño ocupacional, que desde el Marco de Trabajo (American Occupational Therapy Association, 2008) para la práctica de la Terapia Ocupacional estas áreas problemáticas se agrupan en: Trabajo, Educación y Actividades de la Vida Diaria (aludiendo a la sexualidad). La primera de éstas se establece como el área de mayor relevancia en los discursos de los y las entrevistado/as.

En relación al plano laboral, en la actualidad las personas en situación de discapacidad perciben grandes dificultades para ingresar a trabajos remunerados. Tal como lo ilustra Victoria, "... hay diversos profesionales ciegos, que terminaron por trabajar en esos call center. (...) tengo una compañera que estudió pedagogía en castellano, y pasó toda su vida laboral trabajando como telefonista en el ministerio de educación. ¡Siendo profesora! (Extracto entrevista Victoria, pp. 40).
A partir de este relato se visualiza la existencia de prejuicios por parte de la sociedad frente a las habilidades y posibilidades de trabajo de este grupo de personas. De este modo, se promueve un acceso a trabajos donde se mantiene en "privado" la diversidad respecto a otros, o a puestos de trabajo considerados "apropiados" para una persona en situación de discapacidad. Asimismo, se genera una restricción de las opciones de trabajo, generando dificultades para ejercer el propio oficio y/o creando condiciones de sueldo diferenciado, con una baja valoración del trabajo realizado.

Lucas da cuenta de la existencia de otro plano en la misma problemática, al mencionar: "(...) hoy día en la sociedad que estamos tan competitiva, a los empresarios les conviene una persona, entre comillas, normal y sin ningún tipo de discapacidad evidente, porque es mayor el nivel de producción" (Extracto entrevista Lucas, pp. 2), revelando que el alto nivel de competencia en el sistema laboral -que valora la eficacia y eficiencia de sus trabajadores/as- así como, la necesidad de adecuaciones a los puestos de trabajo, restringen las posibilidades de ser empleado.

Respecto al ámbito educacional, Lucas plantea: "(...) Me eché un ramo que era matemática I porque no veía la pizarra (...) con una ansiedad indescriptible fui capaz de hablar con la profesora y pedirle por favor buscáramos la forma (de resolver la situación)." (Extracto entrevista Lucas, pp. 64), evidenciando la dificultad para integrarse al aula de clases y la necesidad de acordar adecuaciones con sus docentes para lograr concretar sus estudios.

Finalmente, en relación al ámbito de la sexualidad Carlos expresa: "...todos somos pobrecitos y qué pena y que no somos unos hueones bandidos, que no fumamos marihuana, que no se drogan, que no se hacen la paja, que no tienen sexo, no hay orgías. ;Oye si somos humanos!" (Extracto entrevista Carlos, pp. 33), denotando, nuevamente, la existencia de estereotipos, infantilización y restricciones, por parte de la sociedad, frente a tópicos que no se consideran ni siquiera problemáticos para este grupo de personas, ya que la sexualidad de las personas en situación de discapacidad se invisibilizada (Centeno, 2014).

\section{J) Propuestas}

En relación a esta categoría, los y las entrevistado/ as destacan el área laboral y el área educacional como ejemplos que reflejan problemáticas para las personas 
en situación de discapacidad. María, al respecto expresa: "Yo creo que, mira, en una persona en situación de discapacidad ya sea por nacimiento o adquirida debería, primero, asegurarse una escolaridad inclusiva"( Extracto entrevista María, pp. 14); en tanto Carlos declara: "Las personas con discapacidad y a los adultos mayores se les debería dar pasaje rebajado en el Transantiago y en el metro en todo horario, porque la gente con discapacidad tiene empleos de más baja categoría, le pagan menos o son gente que vive con pensiones asistenciales (...) (Extracto entrevista Carlos, pp. 25).

Las propuestas manifestadas por ambos entrevistados se vinculan a las necesidades que estos perciben como prioritarias. Una de éstas es el derecho a la educación inclusiva, donde se señala que debe responderse a la diversidad de necesidades educacionales de la población, resguardando la calidad y accesibilidad (física, económica e informativa) sin discriminar ni excluir a las personas cualquiera sea su condición, en cada una de las etapas del ciclo vital. La otra necesidad percibida, de manera implícita, alude al rol del Estado en materia económica y, en relación a esto, se plantea que deben generarse políticas destinadas a fomentar la protección, acceso económico y uso de los servicios específicamente del transporte público, en concordancia a las características laborales de la población, que en el caso de personas en situación de discapacidad, generalmente se condicen a empleos de baja categoría con remuneraciones disminuidas.

\section{DISCUSIÓN Y REFLEXIONES FINALES}

En general, los contextos socio-históricos tienen en común la creación de prácticas de subjetivación que reproducen un modelo de sujeto deseado/ normalizado, de acuerdo a las relaciones y estructuras de poder existentes. Los individuos de una sociedad se configuran a partir de estos patrones, reproduciéndolos a lo largo de su vida. En base a este hecho, es imprescindible comprender que todo individuo, reunirá características que sólo dicho contexto pudo otorgar, por lo tanto, se debe reconocer la transversalidad de la sujeción como generador de sujetos.

Este fenómeno se agudiza de manera significativa con las personas en situación de discapacidad, puesto que constituyen una población que diverge del mode- lo normativo de sujeto, sobre la cual se generan ideas preconcebidas, mediante las figuras de estereotipos y prejuicios, que actúan como expresiones de dicho modelo y, a su vez, como "sujeciones" que envuelven permanentemente a esta población.

Como se señaló anteriormente, esta divergencia frente al modelo normativo se instaura, predominantemente, desde las concepciones de cuerpo. Por consiguiente, se reconoce una tensión entre discapacidad y cuerpo, a partir de la cual se observan dos formas de experimentar la discapacidad: la primera, desde una perspectiva de limitación o desventaja frente a otros; y, la segunda, desde una mirada que valora la diversidad de cuerpos y funcionalidades. Ambas perspectivas son cursadas cíclicamente por los y las entrevistado/as, teniendo en cuenta que el modelo normativo de sujeto emplaza permanentemente a las personas a través de diversos mecanismos de subjetivación.

Sin embargo, tal como se señala en apartados iniciales de esta investigación, toda relación de poder ofrece posibilidades de resistencia que permiten establecer vías de escape frente a situaciones de sometimiento. En el caso de las personas integrantes de agrupaciones se postula la acción colectiva como un espacio que permite compartir significados, aunar fuerzas y representatividad en favor de la consecución de objetivos comunes. Así, el nivel de participación crítica o problematizadora alcanzada por cada agrupación dependerá de la sinergia entre sus objetivos y la existencia de planteamientos que promuevan un cambio ideológico.

A su vez, entre las agrupaciones que integran los entrevistados, se distinguen propósitos relacionados, por un lado, a una perspectiva reivindicativa y, por otro, a una visión problematizadora de la realidad; éstas pueden llegar a coexistir, dependiendo de los intereses y necesidades de la agrupación y sus miembros y los modelos de acción que estos practican.

La Terapia Ocupacional a través de sus prácticas comunitarias puede y debe favorecer la emancipación y el empoderamiento ciudadano, siendo un facilitador en el proceso de construcción de la subjetividad y de la acción colectiva, evitando ejercer prácticas de reproducción desde el poder que otorga el saber científico (Ingleby, 1985). De esta manera, es posible colaborar con el proceso de integración social de las personas en situación de discapacidad; tarea compleja y, por sobre todo, colectiva, en donde la comunidad precisa integrar nuevas concepciones ideológicas que se aproxi- 
men a las perspectivas de "diversidad" a diferencia de la consideración de "anormalidad".

Al finalizar esta investigación, es posible distinguir la interrelación existente entre la subjetividad y la discapacidad en los miembros de las agrupaciones entrevistadas.

El objetivo de este estudio fue comprender las construcciones subjetivas expresadas por sujetos en situación de discapacidad. En un proceso recursivo de interacción, nuestro análisis revela un vínculo de coexistencia entre los términos de subjetividad y discapacidad. La vivencia de la discapacidad, como experiencia de vida, influye sobre la historia personal de todo individuo - en este caso de los y las entrevistado/ as - siendo un elemento esencial para la constitución de la subjetividad. Sin embargo, al comprender la subjetividad como una esfera conformada por múltiples aspectos (asociados a relaciones de poder, cultura, discursos, instituciones, modelos, entre otros) la persona interpreta y da un sentido a la discapacidad de acuerdo a sus propias experiencias de subjetivación. En otras palabras, las personas en situación de discapacidad pueden exhibirse como individuos reproductores o problematizadores de un sistema establecido, capaces de generar prácticas sustentadoras y/o emancipadoras dentro del mismo.

La referencia a este último tipo de prácticas se vincula específicamente a acciones con las cuales se busca producir cambios reales frente a lo que está socialmente determinado. En este sentido, las acciones colectivas contribuyen a la constitución de las subjetividades de sus miembros a partir de las vivencias interpersonales, que permiten multiplicar el potencial de alcanzar un mismo objetivo.

Por último, quisiéramos señalar que las limitaciones considera las posibles variaciones en el orden temático de las entrevistas y la baja representación de diversas agrupaciones/colectivos, lo cual dificulta el hallazgo de tendencias claras en las temáticas mencionadas por los y las entrevistado/as (Boyce \& Neale, 2006). Además de las limitaciones en el estudio para una adecuada saturación de las categorías de análisis, debido a las limitaciones temporales del estudio. Esta exploración inicial, permite motivar a futuras investigaciones que puedan profundizar este tópico con mayor diversidad de agrupaciones/colectivos, lo cual permitirá complementar los resultados con una la mirada más amplia en la construcción de la subjetividad desde la colectividad.

\section{AGRADECIMIENTOS}

A los y las participantes de las agrupaciones, por su tiempo, paciencia y ganas de aportar con esta investigación.

\section{REFERENCIAS BIBLIOGRAFICAS}

Alvarez, E., Gómez, S., Muñoz, I., Navarrete, E., Riveros, M., Rueda, L., Salgado, P., Sepúlveda, R., Valdevenito, A. (2009). Definición y desarrollo del concepto de ocupación: ensayo sobre la experiencia de construcción teórica desde una identidad local. Revista Chilena de Terapia Ocupacional 7 (2007 )1-9. DOI: 10.5354/07175346.2007.81

American Occupational Therapy Association. (2008). Occupational Therapy Practice Framework: Domain \& Process. The American Journal of Occupational Therapy, 62(6), 625 - 683.

Amigot, P. (2005). Relaciones de poder, espacio subjetivo y prácticas de libertad: análisis genealógico de un proceso de transformación de género. Tesis Doctoral. Universidad Autónoma de Barcelona, Barcelona.

Berger, P. L., \& Luckmann, T. (1966). The Social Construction of Reality. New York: Doubleday.

Berger, P. L., Luckmann, T., \& Zifonun, D. (2007). The social construction of reality. Recuperado a partir de http://web.iaincirebon.ac.id/ ebook/moon/\%5BPeter_L._Berger,_Thomas_Luckmann\%5D_ The_Social_Cons(BookFi.org).pdf

Boyce, C., \& Neale, P. (2006). Conducting In-depth interviews: A Guide for Designing and Conducting In-depth Interviews for Evaluation Input. Watertown: Pathfinder International. Recuperado a partir de http://www2.pathfinder.org/site/DocServer/m_e_tool_series_indepth_interviews.pdf?docID $=6301$

Centeno, A. (2014). Simbolismos y alianzas para una revuelta de los cuerpos. Educació Social. Revista d'intervenció socioeducativa, (58), $101-118$

Dejong, G. (1978). Independent Living Movement - Origins, Ideology, and Implications for Disability Research. En Archives of Physical Medicine and Rehabilitation (Vol. 59, pp. 541-541). WB SAUNDERS CO INDEPENDENCE SQUARE WEST CURTIS CENTER, STE 300, PHILADELPHIA, PA 19106-3399.

Droguett, R. F. (2008). Construcción identitaria de la "dis"capacidad visual, en los discursos de personas ciegas que participaron en "! Paque veái!" Recuperado a partir de http://www.um.es/discatif/ documentos/JimenezPizarro.pdf

Egea, C., \& Sarabia, A. (2001). Clasificaciones de la OMS sobre discapacidad. Real Patronato sobre Discapacidad. Diciembre, 2001. Boletín, (50), 16. 
Ema, J. (2004). Del sujeto a la agencia (a través de lo político). Athenea Digital, 6, $1-24$.

Foucault, M. (1978). The history of sexuality. Volume 1: An introduction. Translated by Robert Hurley. New York: Vintage Books.

Garcés Montoya, Á. (2010). A group of youth organizations: Overview of the political participation of youth. Ultima década, 18(32), 61-83. http://doi.org/10.4067/S0718-22362010000100004

García Alonso, J. (2003). El movimiento de vida independiente. Experiencias Internacionales. Madrid: Fundación Luis Vives. Recuperado a partir de http://www.independentliving.org/docs6/alonso2003.pdf

Gergen, K. (1996). Realidades y relaciones: Aproximaciones a la construcción social. Paidós. Recuperado a partir de http://atlas.umss. edu.bo:8080/xmlui/handle/123456789/882

Gil, E. (2004). Ultraindividualismo y simulacro en el nuevo orden mundial: reflexiones sobre la sujeción y la subjetividad. Tesis Doctoral. Universidad Autónoma de Barcelona, Barcelona.

Gutiérrez, P. (2014). Cuerpo, discapacidad y prácticas institucionales: Una visión crítica de su evolución histórica en Chile. Revista Chilena de Terapia Ocupacional, Pag. 107-117. DOI: 10.5354/07175346.2014.35714

Gutiérrez, P., \& Pujol, J. (2009). Etnografía(s) para la terapia ocupacional. En Pimentel, I. Bergma, \& L. Araújo (Eds.), Terapia Ocupacional. Pesquisas Qualitativas. (Vols. 1-Book, 1-Section, pp. 39-66). Belém: Amazonía Editores.

Gutiérrez, P. y Pujol, J. (2016). Occupational Therapy: Autonomy, Govermentaly and Subjectivation. Revista de Estudios Sociales. Universidad de los Andes, Bogota, Colombia (en prensa).

Ingleby, D. (1985). Professionals as socializers: "The Psy Complex". Research in Law, Deviance and Social Control, 7, 79-109.

Intituto Interamericano del niño. (2001). La Inclusión de la niñez con discapacidad. Recuperado a partir de http://www.iin.oea.org/Ninez_Discapacidad.pdf

Krippendorff, K., \& Wolfson, L. (1990). Metodología de análisis de contenido: teoría y práctica. Paidós, Barcelona.

Martin-Baro, I. (1989). Sistema, Grupo y Poder - Psicología Social Desde Centroamérica (II) (1a ed edition). UCA Editores, San Salvador.

Montero, M. (2004). Introducción a la Psicología Comunitaria: DesarroIlo, conceptos y procesos. Paidós. Buenos Aires.

ONU. Organización Naciones Unidas. (2006). Convención sobre los derechos de las personas con discapacidad.

Querejeta, M. (2004). Discapacidad/ Dependencia. Unificación de Criterios de valoración y Clasificación. (Ministerio de Trabajo y Asuntos Sociales Secretaría de Estado de Servicios Sociales, Familias y Discapacidad). Madrid. Recuperado a partir de http://www.indexf.com/lascasas/documentos/lc0181.pdf

Salazar, G., \& Pinto, J. (2002). Historia Contemporánea de Chile V. Niñez y Juventud. LOM, Santiago.

Taylor, S. J., \& Bogdan, R. (1984). Introduction to qualitative research methods: The search for meaning. Wiley, New York.
Valenzuela, K. (2007). Colectivos Juveniles: ¿Inmadurez política o afirmación de otras políticas posibles? Última Década, 15(26), 31 - 52.

WFOT (2010). Declaración sobre la Terapia ocupacional 2010. Federación Mundial de Terapeutas Ocupacionales.

\section{(Footnotes)}

1 Los nombres de las personas han sido cambiados intencionalmente en resguardo de su privacidad 